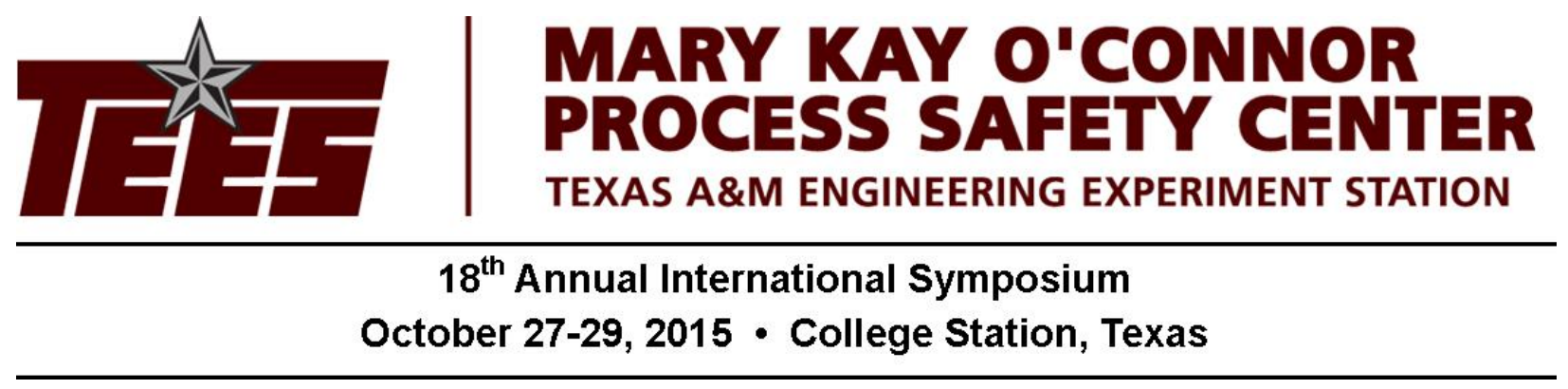

\title{
Building Process Safety Culture at Texas A\&M University at Qatar: A Case Study on Experimental Research
}

\author{
Tomasz Olewski ${ }^{2}$, Monir Ahammad ${ }^{1}$, Syed Quarishy², Ning Gan ${ }^{1}$ and Luc Vechot ${ }^{2}$ \\ Mary Kay O’Connor Process Safety Centre \\ ${ }^{1}$ Texas A\&M University, College Station, Texas \\ ${ }^{2}$ Texas A\&M University at Qatar, Education City, Doha \\ Corresponding author: luc.vechot@qatar.tamu.edu
}

\begin{abstract}
Over the last few years, the importance of establishing and maintaining a positive safety culture in the process industry and its impact on the safety performances of a company have strongly been emphasized by regulatory institutions, academia and very importantly by the process industry itself. A strong safety culture, when everyone in a company feels responsible for safety and acts accordingly, is not achieved overnight as it requires changing behaviors and instilling safety values to individuals. The challenge is there for existing employees of a company but also for new recruits. In the particular case of freshly graduated engineers, it is often only when joining a company that the individual discovers the concept of safety culture and has to buy into it. Academia could play a much better role in training engineers who, not only understand the process safety challenges faced by the industry, but genuinely join the industry with a preestablished positive safety culture developed during the years of their education.

Instilling a process safety culture to future engineers is an area that still requires major efforts from academia. Experimental research at university or college often involves the handling of hazardous substances and processes, with an associated level of risk that need to be minimized. Incidents (major and minor) do happen in university laboratories. It is very common that only major incidents are reported and investigated. Operational deviations, minor incidents, near misses almost never see the light of discussion, although they are opportunities to instill a process safety culture to students, as they are in the process industry.

The objective of this paper is to provide a case study on building process safety culture in a research environment by applying different key aspects of process safety principles. In this study, a series of experiments were analyzed to show how process safety principles starting from inherently safer design and management program can be learnt while performing experimental research. The authors have found that investigating the root causes of near misses have multiple benefits. During the actual experiments no injuries have occurred and even the potential of having injuries was relatively low. However, in the context of this study, selected issues were
\end{abstract}


investigated as accidents, which referred to not being able to successfully perform the experiments or near miss referred to delay of a planned / scheduled experiment. As the matter of fact, all these issues may be treated as time and financial losses. Different aspects of failures such as human factor, process design or inherently safer design and standard operating procedures were discussed via case studies. It was found that having students discussing and presenting the investigation results to other students has greatly improved not only the safety aspects of research but also the productivity and safety culture of the involved researchers.

\section{Introduction}

Regulatory bodies such as the UK Health and Safety Executive (HSE), US Occupational Safety and Health Administration (OSHA) and Environmental Protection Agency (EPA) have recognized and encouraged the companies to nurture a strong safety culture for the reduction of losses. According to OSHA, developing such a culture "should be top priority for all managers and supervisors”. Best practice guides, notes, bulletins are often issued by authorities having jurisdiction to improve the quality of safety cultures. The US Chemical Safety Board (CSB) has often reiterated the importance of safety culture in their investigation of major incidents such as the BP Texas City Refinery [1] and Tesoro Refinery [2]. Researchers have been working on beneficial process safety culture over the last decade. Some of the important directions of this vast research area are related to the definition of safety culture [3], [4], organizational culture and attitude towards safety, diagnosing and measuring safety performances [5].

Despite of the well-recognized importance of safety culture in the process industry, there is still an urgent need for major improvement in the way academia is instilling and cultivating a strong safety culture to undergraduate and graduate students.

Over the last years numerous serious laboratory incident were reported. The CSB has gathered information on 120 different university laboratory incidents over 10 years (2001-2011) after the incident of Texas Tech University Chemistry Laboratory [6]. In 2010, the CSB Chairman John Bresland, suggested to "examine these accidents to see if they can be prevented through the kind of rigorous safety management systems that we [the CSB] and others have advocated in industrial settings" [7].

Academia can tackle safety management and safety culture issues in research laboratories and provide competent engineers to the industry. Experimental research at university or college provides opportunities to instill a process safety culture to students. This paper presents a case study on building process safety culture in a research environment by applying different key aspects of process safety principles. A series of LNG research related experiment have been conducted at the Mary Kay O’Connor Process Safety Centre (MKOPSC) extension at Texas A\&M University at Qatar (TAMU-Qatar). It is to be noted that the results of the research is not presented here but the research work is rather analyzed from a safety stand point to depict different process safety principles that were involved and how a stronger safety culture can be built in the context of the experimental work. The prime objective is to demonstrate the importance and benefits of learning from near misses incidents and perhaps more importantly from early indicators or weak signals.

\section{Elements of Safety Management Systems}

The application of inherently safer design principles and a good safety management program are of paramount importance for safety performances in all steps of a process life cycle.

In the US, facilities that store and use hazardous chemicals are required to comply to the requirements of OSHA's Process Safety Management (PSM) standard (29 CFR 1910.119) and 
the EPA's Risk Management Plan standard (40 CFR Part 68). In Europe, a major accident prevention that covers all moderate and large size plants is implemented through Seveso III directive [8], which is somewhat more general than US approach and built based on Safety Case philosophy. In addition, these requirements are supported by standards on occupational health and safety management systems, both in US [9] and in Europe [10]. In fact, many elements of each approach of managing safety are common in these regulations and standards, and for the needs of this exercise the authors focused mainly on OSHA PSM, although they implemented somewhat Seveso approach as well to evaluate severity of the consequences of the potential incident.

The OSHA PSM is composed of the following fourteen inter-related elements [11]: (a) employee participation; (b) process safety information (PSI); (c) process hazard analysis (PHA); (d) operating procedures; (e) training; (f) contractors; (g) pre-start up safety review; (h) mechanical integrity; (i) hot works permit; (j) management of change (MOC); (k) emergency planning and response; (l) compliance audits; (m) trade secrets; and (n) incident investigation.

Experiments performed at university do not have the level of complexity or the scale of a process plant and are not subject to the above mentioned regulations.

A group of three students in charge of the preparation and the execution of a series of experimental work have tried to apply selected relevant elements of PSM (b, c, d, f, k, l and k) to their activities throughout the project. The supervisors of this work, while closely monitoring the progress and ensuring that the work was performed in the safest conditions, left a certain degree of freedom to the students to encourage the learning process, particularly learning from mistakes.

\section{The case study}

The work presented in this paper was done in the context of a major research project aiming to improve the prediction of the consequences Liquefied Natural Gas (LNG) spill on concrete ground. The project particularly focuses on the modelling of LNG vapor generation rate (source term). It involves a series of spill experiments designed to measure the vaporization rate of a cryogenic liquid pool along with the heat flux to the pool from the concrete ground. The experiments are performed at several scales:

- laboratory scale $\left(7 \times 10^{-3} \mathrm{~m}^{3}\right)$ at TAMU-Qatar

- medium scale (up to $32 \times 10^{-3} \mathrm{~m}^{3}$ ) at Fire Station 2 of the Ras Laffan Industrial City (RLIC)

- large field scale (up to $40 \mathrm{~m}^{3}$ ) at the Ras Laffan Emergency and Safety College (RLESC) Liquid nitrogen $\left(\mathrm{LN}_{2}\right)$, liquid oxygen $\left(\mathrm{LO}_{2}\right)$ and $\mathrm{LN}_{2} / \mathrm{LO}_{2}$ binary mixtures (liquid air) are used as a safer analogue of LNG. Experiments with LNG will be done only at large scale at RLESC. The experimental work included three main phases (Figure 1) somewhat comparable to the typical phases of an industrial project:

- Preparation of the experimental setup (comparable to the Front End Engineering Design, FEED and Detailed Engineering Design)

- Execution of the experiments (comparable to start-up, operations, and regular or emergency shut-down)

- Data Analysis (comparable to incident investigations and process optimization)

Purchasing/procurement, approval procedures logistics and scheduling were also required during the project making it closer the requirement of a real industrial project. Thus, a simple 
experimental project might give sufficient background to learn industrial good practices and the general philosophy of project and safety management.

In this study, only the work for the medium scale experiments at RLIC with $\mathrm{LN}_{2}, \mathrm{LO}_{2}$ and $\mathrm{LN}_{2} / \mathrm{LO}_{2}$ mixture are discussed.

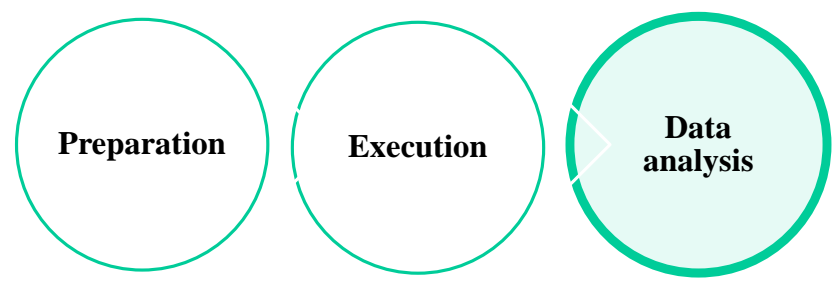

Figure 1: Project Steps

\subsection{Preparation: design and building of the experimental setup}

The medium scale experiment setup was built at our laboratory at TAMU-Qatar in Doha. It consisted of an instrumented box (liquid capacity of $32 \times 10^{-3} \mathrm{~m}^{3}$ ) with a concrete base and steel walls (Figure 2) into which cryogenic liquid can be poured to form a liquid pool. Eleven thermocouples and two heat flux sensors were embedded into the concrete base at four different depths to monitor the temperature and heating flux profiles inside the concrete. The sides of concrete box were insulated using polystyrene to limit the heat flux from the walls and favor unidirectional vertical heat flux from the concrete base to the pool.

Once built the box was transported to RLIC where a wind tunnel was specially built to accommodate the box while controlling / limiting air flow above the liquid pool and limiting the pool exposure to solar radiation. In the tunnel the box was placed on a balance to monitor the vaporization rate of the liquid.

All sensors' output were connected to a data acquisition system at a remote location.

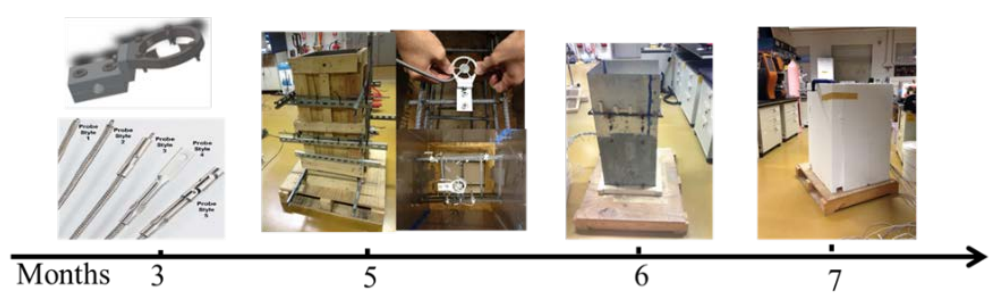

Figure 2: Experimental setup and timeline. From left to right: thermocouples, concrete box preparation, installation of heat flux sensors, built concrete box with steel walls, and final setup with polystyrene insulation on the sides

$\mathrm{LN}_{2}, \mathrm{LO}_{2}$ and $\mathrm{LN}_{2} / \mathrm{LO}_{2}$ binary mixtures were discharged from a 180 liters storage cylinder (1.5 $\mathrm{m}$ high and $0.6 \mathrm{~m}$ diameter).The maximum allowable working pressure (MAWP) of the cylinder was 24 barg (348 psig) and the relief pressure control valve was set at 15 psi (about 1 barg). The cylinder was delivered and unloaded by a contractor. The cylinder was delivered in a basket to ensure its stability. The cryogen was discharged through a 16 meter long, $1 / 2$ inch diameter; rubber foam insulated cryogenic hose with phase separator at the end. 


\subsection{Execution of the experiments}

The discharge was controlled manually by the research staff through the manual valve located on the cylinder. A relatively long length hose was chosen to ensure a safer distance of the operator from the discharge location. The mass loss of vaporizing liquid was recorded every second and a $30 \mathrm{~s}$ averaged vaporization rate was calculated. Liquid was discharged into the containment as long as it reached its upper operational limit (equivalent of $0.29 \mathrm{~m}^{3}$ ), which last approximately 5 minutes. The box was covered with a polystyrene lid to limit the effect of convective heat transfer to the pool. The liquid vaporization rate calculated based on mass loss measurement was directly proportional to the total heat flux to the pool, which includes the conduction through the ground (concrete base), walls and lid. The photos of the experiment are shown in Figure 3.
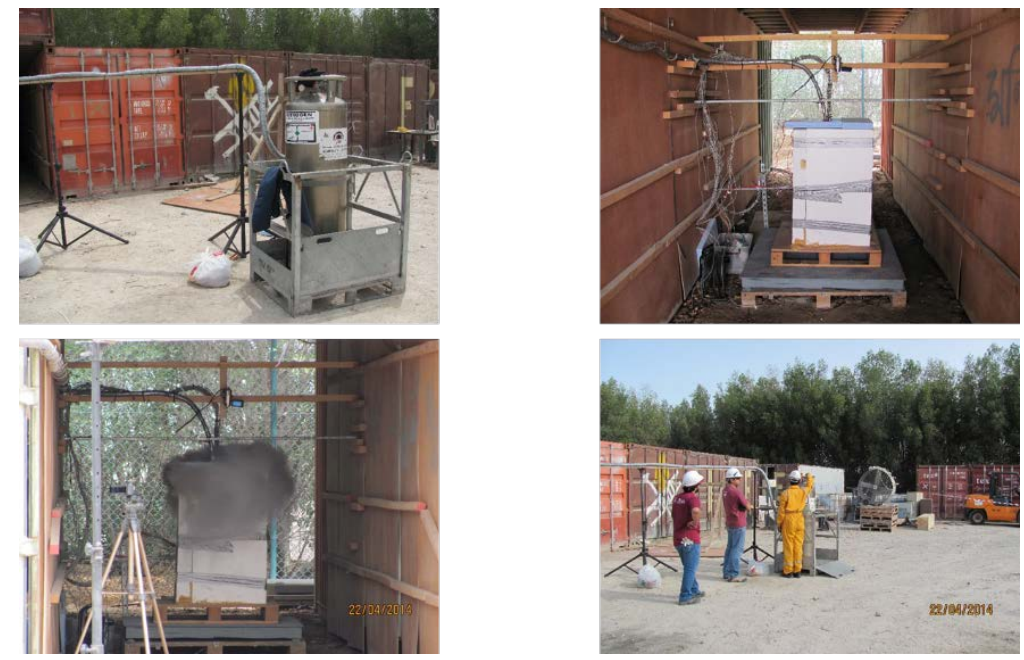

Figure 3: Liquid nitrogen and liquid oxygen spill over concrete experiment at RLIC

\section{Practiced Safety Management Elements during the Case Study}

As mentioned, a group of three students in charge of the preparation and the execution of a series of experimental work have tried to apply selected elements of PSM (b, c, d, f, k, l and k) to their activities throughout the project. The analysis and discussion on these elements was done during and after the experiment was performed.

\subsection{Process Safety Information:}

According to OSHA, process safety information are complete and accurate written information concerning process chemicals, process technology, and process equipment and are essential for the PHA. In our case, process safety information includes but was not limited to

- Material Safety Data Sheet of $\mathrm{LN}_{2}, \mathrm{LO}_{2}$, and $\mathrm{LN}_{2} / \mathrm{LO}_{2}$ mixture

- Experiment Start-up, Operation, and Shut-down Procedure

- Emergency Action Plan and Response Procedure

- Design of the experimental setup and User manuals of the equipment (Balance, Data Acquisition System)

- Consequence Analysis Report 
- Permits, consents, licenses and authorization to conduct the experiment at RLIC

- Site Layout and Occupancy Data

- Local Weather Data

- Specifications of Vendor's Equipment (Cryogenic Liquid Tank) and certification of vendor

\subsection{Process Hazard Analysis (PHA)}

The PHA is one of the most important elements of the process safety management program. It is an organized and systematic effort to identify and analyze the significance of potential hazards associated with the processing or handling of highly hazardous chemicals. It provides the input for frequency, consequence and risk analysis. A variety of methods can be used to conduct a PHA and the method selected will depend on the complexity, the size and maturity of the process and operational experience of the team members. In this study, a general qualitative approach has been taken. The details of the PHA methodology conducted in this case study are presented below.

\section{Risk Ranking and Management Procedure}

Risk in general is defined as a measure of potential economic loss or human injury in terms of the probability of the loss or injury occurring and their magnitude. Risk thus comprises of two variables; magnitude of consequences and the probability of occurrence. The results of the consequence modelling and the frequency of the scenarios were placed on a risk matrix with given risk criteria as shown in Figure 4. The consequence severity of any perceived hazardous scenario is identified as 0 to 4 where 0 indicates the minimum and 4 indicates maximum. Similarly, a qualitative approach is taken to define the frequency of occurrence of the perceived scenario as shown on the top of the risk matrix. A 0 likelihood indicates that it is certain the event will not occur on the other hand 4 indicates the certainty of the event happening. Each cell of the matrix indicates the risk level. Red cells indicate the intolerable risk level. No operations or experiments in this case can be conducted if any perceived scenario falls in this zone. Proper risk mitigation actions are needed to reduce the risk level to at-least to the next level which is yellow zone. The target of the research group is to operate in the green zone - fully acceptable level of risk. The work is allow if the level of risk is yellow under some conditions. First, such a case should be reviewed to introduce additional controls, if possible. Second, if proper consequence prevention and mitigation measurements are in place, it has to be demonstrated that the risk is at as low as reasonable practicable level. Then it is assumed that the risk is tolerable and acceptable and the team may proceed with caution, monitoring and maintaining strictly preventive and mitigation measurements. 


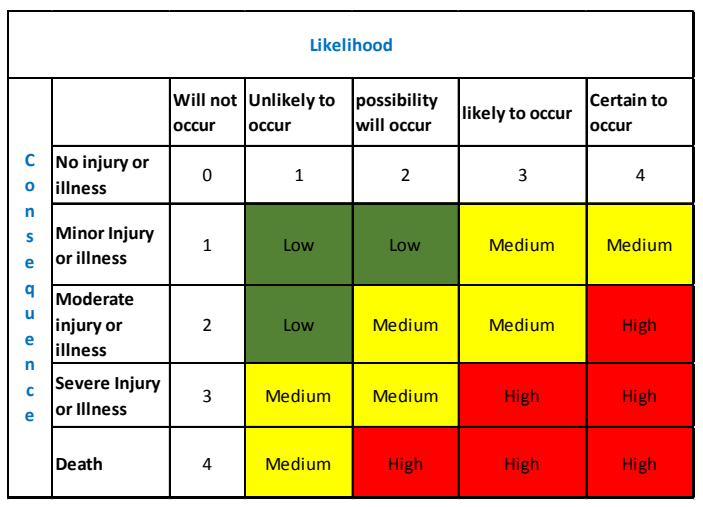

Low risk - Fully acceptable. Monitor and manage.

Medium risk - Tolerable and acceptable risk as long as demonstrated that the risk is at as low as reasonable practicable level. Review and introduce additional controls if possible. Monitor and maintain strict measures.

High risk - Not acceptable. Do not proceed!

Figure 4: Risk matrix

\section{Hazard Identification}

Preliminary Hazards Analysis method was used to identify the hazards associated to the experiments. Brainstorming sessions were organized for hazard identification via answering a series of questions considering different phase of the experiments including construction, installation and execution. Several hazards with the associated safeguards were identified and discussed. Some recommendations were also given to reduce some risks to lower level. A typical example of hazard identification results (selected identified accident scenarios) and risk assessment summary is given in Table 2 (where severity and probabilities are ranked from 1-4) and some critical elements are summarized below.

There is no possibility of fire or vapor cloud explosion as the cryogenic liquids used are not flammable. However, as cryogenic liquids are extremely cold, any contact of bare body parts with the liquid or cold surface will cause frostbites and cold burns. When released in large amount, the inhalation of high concentrations of $\mathrm{N}_{2}$, if the level of drops below $16 \%$ in air, can cause rapid suffocation and death. Symptoms at lower concentrations (if $\mathrm{O}_{2}$ level drops below 19.5\%) may include loss of consciousness and mobility, dizziness and nausea. $\mathrm{O}_{2}$ is a strong oxidizer and can enhance fires or even the potential for fire. Continuous $\mathrm{O}_{2}$ inhalation of concentrations higher than $75 \%$ may cause nausea, dizziness, respiratory difficulty, cough, sore throat and convulsion.

Cryogens produces large volumes of gas when they vaporize. One volume of $\mathrm{LN}_{2}$ and $\mathrm{LO}_{2}$ will respectively expand to produce 696.5 and 861 equivalent volume of gas. Both gases are invisible. However the presence of the very cold gas during the release is actually visible as a 
white fog, which is condensed air moisture. The suffocation was considered as credible scenario, if the person is exposed to white cloud (high concentration of cold gas) followed an accidental release of $\mathrm{LN}_{2}$. In such a case, an evacuation of personnel (if present) from the shelter was recommended, even though it was open from two sides to ensure ventilation. Outside of the shelter, there is an open air space and the nitrogen concentration will decrease quickly. Suffocation was not considered as a credible scenario during the release of liquid air or oxygen. As mentioned, the cylinder was equipped with a pressure relief device to control the internal pressure at 15 psi when the MAWP was 358 psi and the cylinder was equipped with an additional rupture disc. To protect from extremely cold temperatures, the pipe was insulated and the operator wore adequate personal protective equipment (PPE): long sleeve clothes, pants, safety shoes, cryogenic apron and gloves, safety glasses and helmet. 
Table 1: The example of hazard identification outcome (selected identified an accident scenarios) and risk assessment.

\begin{tabular}{|c|c|c|c|c|c|}
\hline Hazard & $\begin{array}{c}\text { Identified accident } \\
\text { scenario } \\
\text { (cause-consequence) }\end{array}$ & $\mathbf{P}^{*}$ & $\mathrm{~S}^{*}$ & Risk & Risk control strategy \\
\hline $\begin{array}{l}\text { Leaks/Spills } \\
\text { of liquid } \\
\text { nitrogen }\end{array}$ & $\begin{array}{l}\text { The overheating may } \\
\text { lead to the over } \\
\text { pressurization of the } \\
\text { cylinder and an excessive } \\
\text { release rate during the } \\
\text { spill into the box, which } \\
\text { is in the wind tunnel } \\
\text { shelter. In case of liquid } \\
\text { nitrogen spill, this may } \\
\text { result in the } \\
\text { concentration of oxygen } \\
\text { in the air to drop below a } \\
\text { safe limit with potential } \\
\text { for asphyxiation, for } \\
\text { personnel if were to be } \\
\text { present in the wind } \\
\text { tunnel. }\end{array}$ & 1 & 4 & Medium & $\begin{array}{l}\text { The liquid pipe is insulated and } \\
\text { sheltered and the cylinder is insulated to } \\
\text { limit solar radiation. } \\
\text { The experiment is performed in the } \\
\text { open air (wind tunnel is open from two } \\
\text { sides) and the nitrogen concentration } \\
\text { will decrease quickly with the distance. } \\
\text { High concentration of nitrogen during } \\
\text { the experiment is present only very } \\
\text { close to the box - personnel should not } \\
\text { put the head close to the box. } \\
\text { The presence of personnel in the shelter } \\
\text { should be kept as short as possible. In } \\
\text { the case of an accidental release (box } \\
\text { catastrophic failure), evacuate all } \\
\text { personnel from the shelter. } \\
\text { All personnel during the experiment is } \\
\text { located at remote control room } 40 \text { m } \\
\text { away upwind of the spill. } \\
\text { The cylinder is operated outside of the } \\
\text { shelter, about } 15 \text { m away of the spill. } \\
\text { Self-contained breathing apparatus } \\
\text { (SCBA) may be required, if large } \\
\text { amount of LN }{ }_{2} \text { is released. } \\
\text { Wait for ventilation of the shelter prior } \\
\text { to entry. } \\
\text { Exclusion distance is } 2 \mathrm{~m} \text { from the } \\
\text { shelter upwind. Restricted human } \\
\text { presence downwind. }\end{array}$ \\
\hline
\end{tabular}




\begin{tabular}{|c|c|c|c|c|c|}
\hline Explosion & $\begin{array}{l}\text { In case of overheating of } \\
\text { the cylinder due to } \\
\text { excessive solar radiation, } \\
\text { there is a potential for } \\
\text { cylinder burst and } \\
\text { physical explosion, with } \\
\text { potential for serious } \\
\text { injuries to people or } \\
\text { fatalities. }\end{array}$ & 1 & 4 & Medium & $\begin{array}{l}\text { The cylinder is insulated to limit solar } \\
\text { radiation. } \\
\text { The cylinder is equipped with pressure } \\
\text { relief valve (set at } 22 \text { psi) and rupture } \\
\text { disc (set at } 30 \text { psi). } \\
\text { Maximum Allowable Working Pressure } \\
\text { for the cylinder is } 348 \text { psi ( } 24 \text { bar), } \\
\text { which about } 16 \text { time higher than the set } \\
\text { pressure of the pressure relief valve. } \\
\text { The cylinder is installed inside a heavy } \\
\text { duty cage to ensure the stability and } \\
\text { prevent flying. } \\
\text { All personnel during the experiment is } \\
\text { located at remote control room } 40 \mathrm{~m} \\
\text { away of the cylinder. } \\
\text { Emergency responders are located very } \\
\text { closed to the experimental location and } \\
\text { informed about experiment hazards and } \\
\text { risk, and emergency response plan is } \\
\text { communicated. }\end{array}$ \\
\hline \begin{tabular}{|l|} 
Heavy \\
object drop \\
hazards
\end{tabular} & $\begin{array}{l}\text { Foot injuries may happen } \\
\text { during the move of heavy } \\
\text { objects. }\end{array}$ & 2 & 1 & Low & $\begin{array}{l}\text { Wear safety shoes at all time. } \\
\text { Limit a movement of heavy objects. }\end{array}$ \\
\hline \begin{tabular}{|l|} 
Burn hazard \\
from the low \\
temperature \\
of cryogen
\end{tabular} & $\begin{array}{l}\text { Frostbites are possible if } \\
\text { bare body parts are in } \\
\text { contact with cryogenic } \\
\text { liquid or cold surfaces. }\end{array}$ & 2 & 1 & Low & $\begin{array}{l}\text { Always wear cryogenic gloves and } \\
\text { apron, long sleeves and long legs } \\
\text { clothes, safety shoes and goggles when } \\
\text { handling cryogenic liquid to avoid cold } \\
\text { burn. }\end{array}$ \\
\hline
\end{tabular}

*P: Probability; S: Severity of the consequences

\section{Consequence and Frequency Analysis}

In order to identify risk, the first step after generating potential accident scenarios is to identify the consequences of those potential accident scenarios. In this study a spectrum of potential consequences of accidental spill of cryogenic liquids have been constructed and studied. Each accident scenario was studied for two different weather conditions namely the "worst case" and the "alternate case". The worst case condition was considered for slow wind speed $1.5 \mathrm{~m} \mathrm{~s}^{-1}$ and stable atmospheric air stability class $\mathrm{F}$ (clouded sky and no solar radiation). The alternate case did represent a prevalent weather condition, namely $5 \mathrm{~m} \mathrm{~s}^{-1}$ wind speed with the atmospheric stability class type D (sunny day). Both scenarios assumed an ambient temperature of $35^{\circ} \mathrm{C}$ and 70\% humidity (typical for Qatar). The considered scenarios included:

- Scenario 1: Vaporization of the cryogenic liquid pool during normal operation, i.e. vaporization from $0.25 \mathrm{~m}^{2}$ pool area with a maximum pool depth of $0.4 \mathrm{~m}$. The chosen pressure of the cylinder is $15 \mathrm{psi}$ ( $1 \mathrm{barg}$ ) representing normal operating pressure.

- Scenario 2: Full bore rupture from $1 / 2$ inch hose and spill of cryogenic liquid on the ground. The chosen pressure of the cylinder is also 15 psi ( 1 barg) representing normal operating pressure. 
- Scenario 3: Release due to the catastrophic failure of storage tank $\left(0.180 \mathrm{~m}^{3}\right.$ liquid cylinder) at a burst pressure equal to the MAWP of the cylinder (24 barg).

These scenarios were studied for $\mathrm{LN}_{2}$ and $\mathrm{LO}_{2}$ using PHAST 6.7, a commercial consequence modelling software. The releases of LN2/LO2 mixture (liquid air) vapor dispersion were not considered hazardous with regards to inhalation as it approximately represents air.

Two levels of concern (LOC) vapor concentration were analyzed for $\mathrm{N}_{2}$ and $\mathrm{O}_{2}$ as shown in Table 1. LOC-1 represents the first negative health effect to people and LOC-2 represents potential fatalities (although in case of oxygen it is a rather conservative approach). Both levels are correlated to the actual level of $\mathrm{O}_{2}$ in air. It was assumed that $\mathrm{O}_{2}$ concentration below $16 \%$ and above $75 \%$ are fatal (LOC-2). $\mathrm{O}_{2}$ concentration between 19.5 and 23\% are considered safe with no adverse effects on people.

Figure 5 and Figure 6 show the results of the consequence analysis of the scenarios 1 and 3, respectively:

- Scenario 1 with $\mathbf{L O}_{2}$ : No LOC-2 zone (fatalities) was identified. LOC-1 (minor health effect - blue line in Figure 5 does not extend beyond a distance of $3.3 \mathrm{~m}$ downwind. There is no operator present downwind of the box thus this scenario does not pose credible negative effects to people, if procedures are followed. Therefore, the risk of negative consequences of this scenario can be considered as minimal and acceptable. Therefore, this scenario is not needed to be further studied.

- Scenario 3 with $\mathbf{L O}_{2}$ : The release of the full oxygen inventory due to catastrophic failure of storage tank create life-threatening zone (LOC-2, red line in Figure 6) of $10 \mathrm{~m}$ diameter located more or less at the center of the release. The LOC-1 zone is about $70 \mathrm{~m}$ wide and the center of the cloud is about $15 \mathrm{~m}$ downwind of the release point (blue line in Figure 6). Both consequences present potential for injuries only to the operator during the manual valve operation, which is short and last less than 5 min and the hazardous clouds do not reach the control room which is located $40 \mathrm{~m}$ away upwind of the box. Since, the material is oxygen which does not have significant threat when vaporized, the severity of this event was considered as 3. However, engineering judgements and previous experience dictates that the frequency of this event occurring is 1 . Therefore this scenario falls in the yellow zone and the experiments can still be preceded with caution.

Table 2: The levels of concern for liquid nitrogen and liquid oxygen releases (correlating actual oxygen concentration in air is given in the brackets)

\begin{tabular}{|c|l|c|c|}
\hline Level & \multicolumn{1}{|c|}{ Description } & $\begin{array}{c}\text { LOC of liquid nitrogen, } \\
\text { \% }\end{array}$ & $\begin{array}{c}\text { LOC of liquid oxygen, } \\
\text { \% }\end{array}$ \\
\hline LOC-1 & $\begin{array}{l}\text { first negative health effect to } \\
\text { the people }\end{array}$ & $\begin{array}{c}6.25 \\
(19.5 \% \text { of OX in air })\end{array}$ & $\begin{array}{c}2.78 \\
\text { (23\% of OX in air) }\end{array}$ \\
\hline LOC-2 & fatalities & $\begin{array}{c}23.1 \\
\text { (16\% of OX in air })\end{array}$ & $\begin{array}{c}68.43 \\
\text { (75\% of OX in air) }\end{array}$ \\
\hline
\end{tabular}

The frequency of each identified scenario was not evaluated through the rigorous techniques used in standard quantitative risk assessment but rather on the basis of the number and qualitative reliability of the existing barriers e.g. relief devices, ventilation, presence of procedure. Besides the existing engineering barriers, several other frequency reduction measures 
were considered when needed. This includes exclusion zones, emergency response plan, and safe operating procedures. Credit has been taken for the presence of a qualified emergency response team of RLIC throughout the experiment duration.

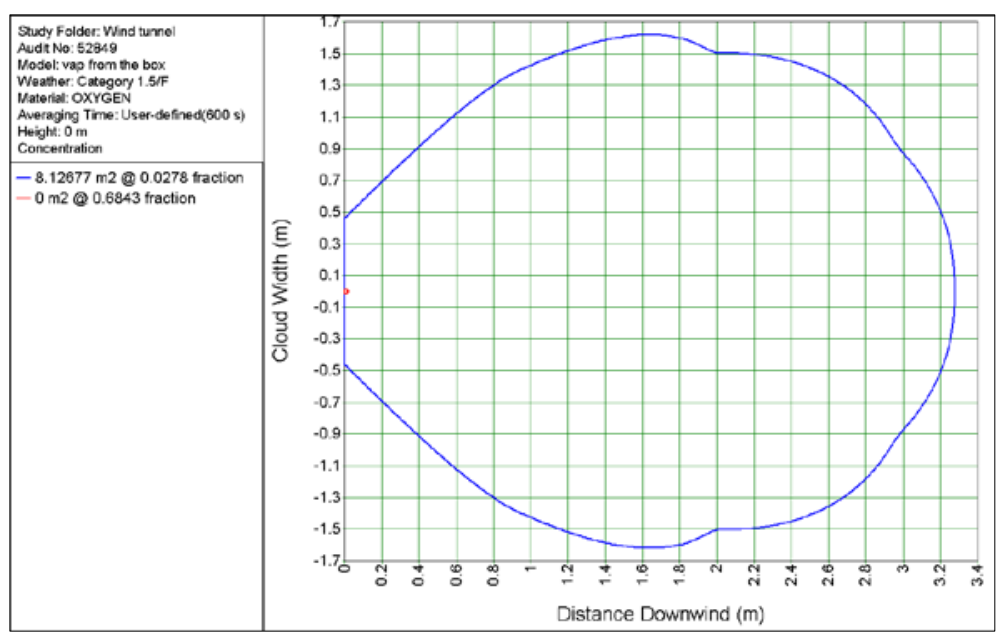

Figure 5: Scenario 1- Maximum concentration footprint of dispersed oxygen gas (exceeding air) towards downwind direction

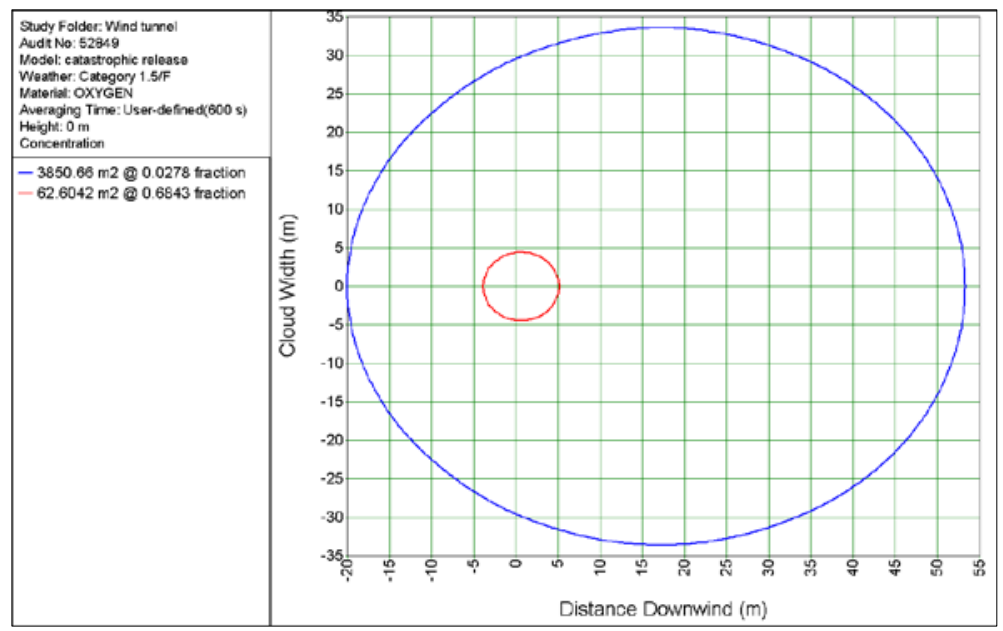

Figure 6: Scenario 3- Maximum concentration footprint of dispersed oxygen gas (exceeding air) towards downwind direction

\section{Risk Communication}

The experiments were to be performed at RLIC operated by Qatar Petroleum (QP). The results of the risk assessment were presented to Qatar Petroleum (QP) representatives and staff. Although QP owns many operational sites/plants, none of them is in the near proximity of the experimental site. Nevertheless, the risks associated with conducting these experiments were communicated via written report, site visit and brainstorming meetings. The assessed safety distances were discussed and approved in those meetings and recommendation was made to restrict the site only to authorized persons with proper Personnel Protective Equipment (PPE). 


\subsection{Emergency Response Plan}

Emergency actions should be planned and drills must be performed regularly to tackle unwanted release of hazardous material. Industries are required to develop and implement an emergency action plan for the entire plant, not just the processes in accordance with the provisions of 29 CFR 1910.38(a) and 29 CFR 1910.120(a), (p) and (q). The plan needs to be comprehensive, including notification to emergency responders, operational responses and precautions to protect other employees and the public. Likewise, we planned emergency actions and the emergency response plan was discussed with the fire fighters and emergency responders of the industrial city. An emergency response team from RLIC Fire Station-2 was on stand-by during the commissioning of the experimental set up and the execution of the experiment.

\subsection{Use of Third Party Contractors}

The choice of contractors to perform work on and in the vicinity of processes that involve highly hazardous chemicals, needs to be closely controlled through a screening process. In our case, we needed a contractor to supply the cryogenic liquid cylinders at the test site. The chosen contractor did performed similar work with another research group and was recommended for the job. The representative of our research group has visited a contractor site to discuss the job and to evaluate the contractor, which resulted in positive results. Couple of days before each experiment, the contractor was being informed about the experiment date and quantity of liquid needed for delivery.

\subsection{Operating Procedures}

Operating Procedures are clear instructions for conducting activities safely. Operating procedures describe tasks to be performed, data to be recorded, operating conditions to be maintained, samples to be collected, and safety and health precautions to be taken. The procedures need to be technically accurate, understandable, up to date, and reliable and they reflect current operations. The process safety information and the result of process hazards analysis were used as a resource to established and/or improve the operating procedures and practices. Written checklists were prepared in order to follow and document each procedure.

\subsection{Experimental incidents and their investigation}

Incident can occur because of numerous reasons. However, the culture of learning from incidents especially those that are not costly, i.e. near misses, challenges to safety systems or even the deviations from the design of the process can significantly reduce the number of incidents. The analysis of the root causes of such incidents enhance safety management systems and make them more capable of reducing risk and improve safety in many aspects. We focused on the analysis of events that we categorized as near-misses. Though sometime near misses are considered as lagging indicator of process safety, the root cause analysis of the near miss incident can give us very useful leading indicators [12]. Three near misses while carrying out the experiments have been identified and analyzed. 
Near Miss 1: Ineffective communication leading to the delay of the field experiments

While preparing and performing the experiments, the research team had to travel a distance of about $80 \mathrm{~km}$ (1 hour drive approximately), from the University to the experimental facility at RLIC every morning of each preparation and experimental day. Every time, the cryogenic liquid delivery was scheduled on early morning of the experiment day. The following incidents happened:

- The contractor, cryogenic liquid supplier, forgot to provide the cryogenic hose used to connect the cylinder with the spill box. Consequently, the research team was not able to perform the experiment. This led to an unexpected delay in the work to be performed.

Using the Fault Tree Analysis (FTA) for this incident, the cause leading to the major event can be understood as follows:

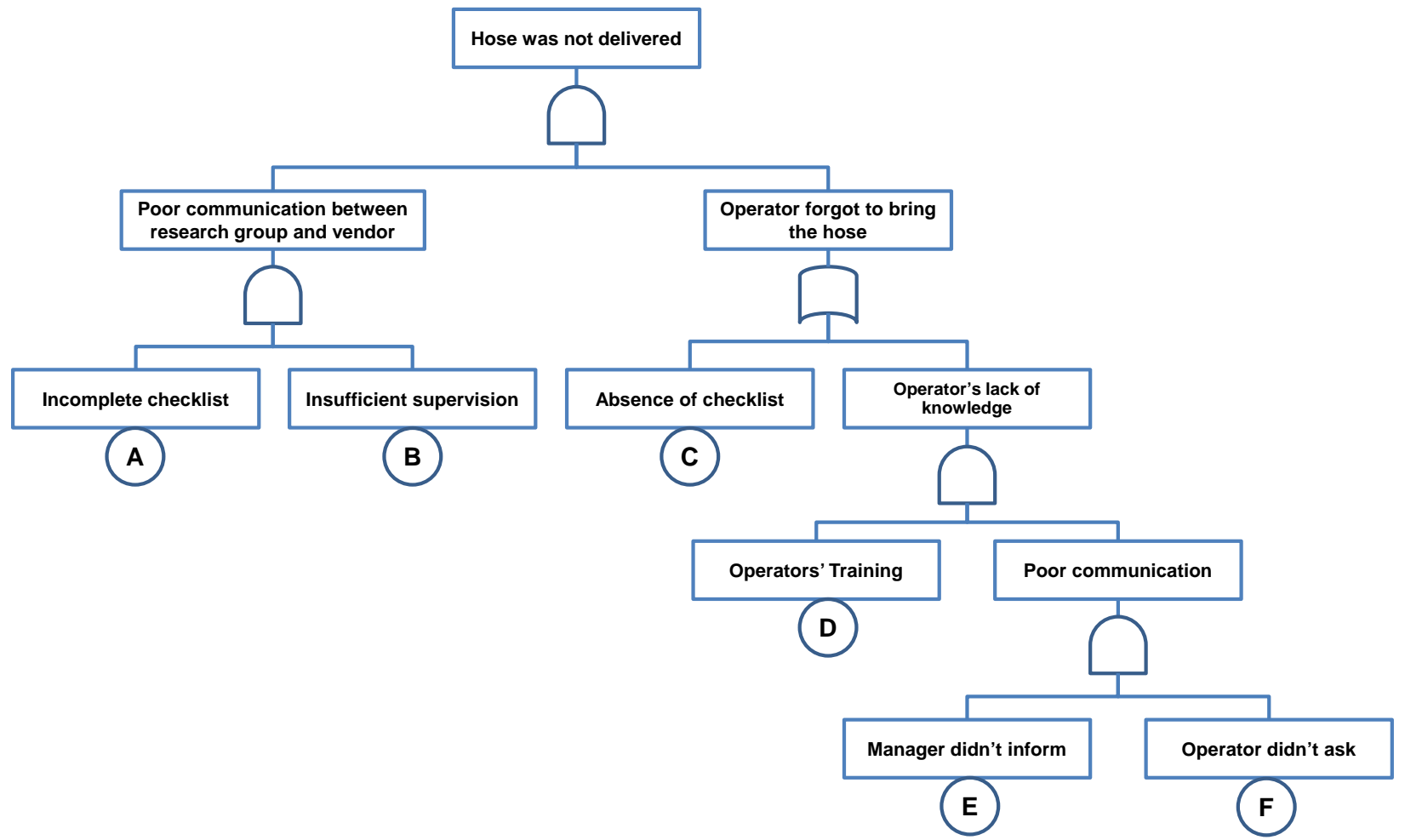

Figure 7: Fault Tree Analysis for Near Miss 1

The basic events for the incident were identified as: a) Incomplete checklist prior to field experiment, b) Insufficient supervision in the research team, c) Vendor is lack of the delivery checklist, d) Operator is lack of training, e \& f) Poor communication between the manager and the operator inside the vendor company.

Researchers experienced also another similar near miss that also happened due to the ineffective communication. During normal purchase process, the $\mathrm{LN}_{2}$ supplier required an official letter and written communication (email) from the research team before every order. The research team, di not only relied on those two, but also made it a habit to call the contractor a day or two before every supply to confirm the delivery. As a result, a call from the research team side also became a norm to the supplier, while never written. For this particular incident, the student responsible for the communication with the contractor did send documents and email as expected, but did not 
make the phone call a day before experiment assuming that everything was clear in the written communication. On the day of the experiment, the contractor did not deliver the $\mathrm{LN}_{2}$ explaining that they assumed that the experiment was cancelled as they did not receive the call. The experiment had to be postponed by several days.

In the case of the first incident, we have identified the root cause as lack of verification of the vendor and lack of communication with the vendor prior to the experiment, which can ensure the requested items would indeed be delivered. Prior to this incident, the hose was always clearly requested to the contractor and the contractor had always delivered it accordingly. However, this time the cylinder was requested and it was assumed on our side that the hose would be delivered as usual. Unfortunately, the contractor's driver who used to deliver was changed and the new driver was not aware of the need to systematically bring the hose.

Performance of routine tasks day by day in familiar condition may cause this kind of lapse and one's attention can be focused on something else than the task to be performed. The root causes of these events are: a) Lack of control on the contractor, b) Lack of followed checklists, and c) Lack of communication. The example of the hose also showed that the change of driver contributed to the issue. This highlighted the importance of managing changes. Lesson learnt: the dependence on human memory should be supported by structured methods, like checklists, to reduce human error.

\section{Near Miss 2: Over pressurized air released through pressure relief valve}

During the second day of the experiment, liquid air vapor was released unintentionally through the relief valve. After each release of the liquid from the cryogenic tank, the pressure in the cylinder drops down, which is normal and each time before the following spill experiment the pressure has to be built-up by opening another valve until the pressure increases back to its desired level (in this case 15 psi). The pressure building process being time consuming, the operator does not wait next to the cylinder under very strong sun, and usually goes inside the control room protecting him from solar radiation. He only goes periodically to check on the pressure.

During this particular day, the same procedure was followed and after the first spill experiment the operator opened the pressure build-up valve and went to control room. However, before he went back to cylinder to check the value, the pressure had already increased to the pressure relief valve set pressure (at 22 psi). This resulted in a noisy whistling high pressure release from the relief valve, which alarmed the operator, who went to close the valve. Normal operation was resumed shortly after.

Usually, the pressure build up process, the cryogenic gas release and the cryogenic liquid release are executed by opening different valve on the top of the liquid cylinder (see Figure 8). Typically, the cryogenic liquid cylinder usage involves three stages:

1) Pressure Building Circuit - The Pressure builder is used when the demand for gas or liquid is greater than the cylinder natural productive capacity. This circuit builds gas pressure by removing liquid from the bottom of the tank, and passing it through a coil that is soldered to the outer skin of the tank. The exposure to heat from contact to the tank exterior causes the liquid to convert to a gaseous state as it moves back to the top of the tank. A pressure building regulator controls the gas flow in this circuit.

2) Gas Use Circuit - Similar to the pressure building circuit, liquid is taken from the bottom of the inner vessel and run through multiple coils that are soldered to the outer vessel, to produce gas. This gas is available for low or high pressure applications. 
3) Liquid Withdrawal Circuit - This circuit takes liquid from the bottom of the tank and delivers it directly to the liquid valve.
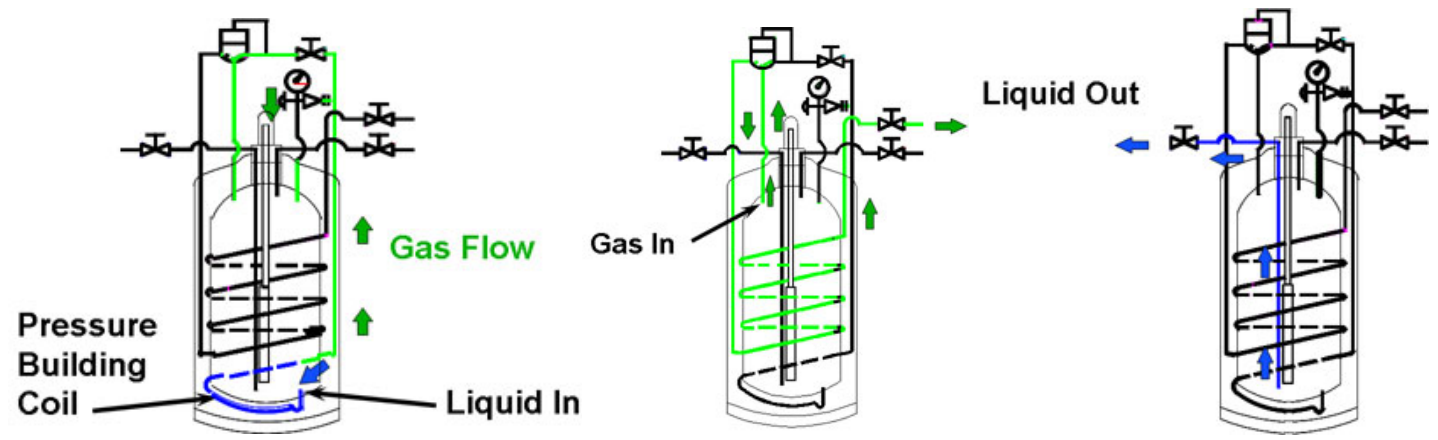

Figure 8: Schematic diagram for basic operation of Liquid cylinder. (Left: Pressure Building

Circuit; Center: Gas Use Circuit; Right: Liquid Withdrawal Circuit.)

The Fault Tree Analysis, the identified basic events for near miss 2 are in Figure 9.

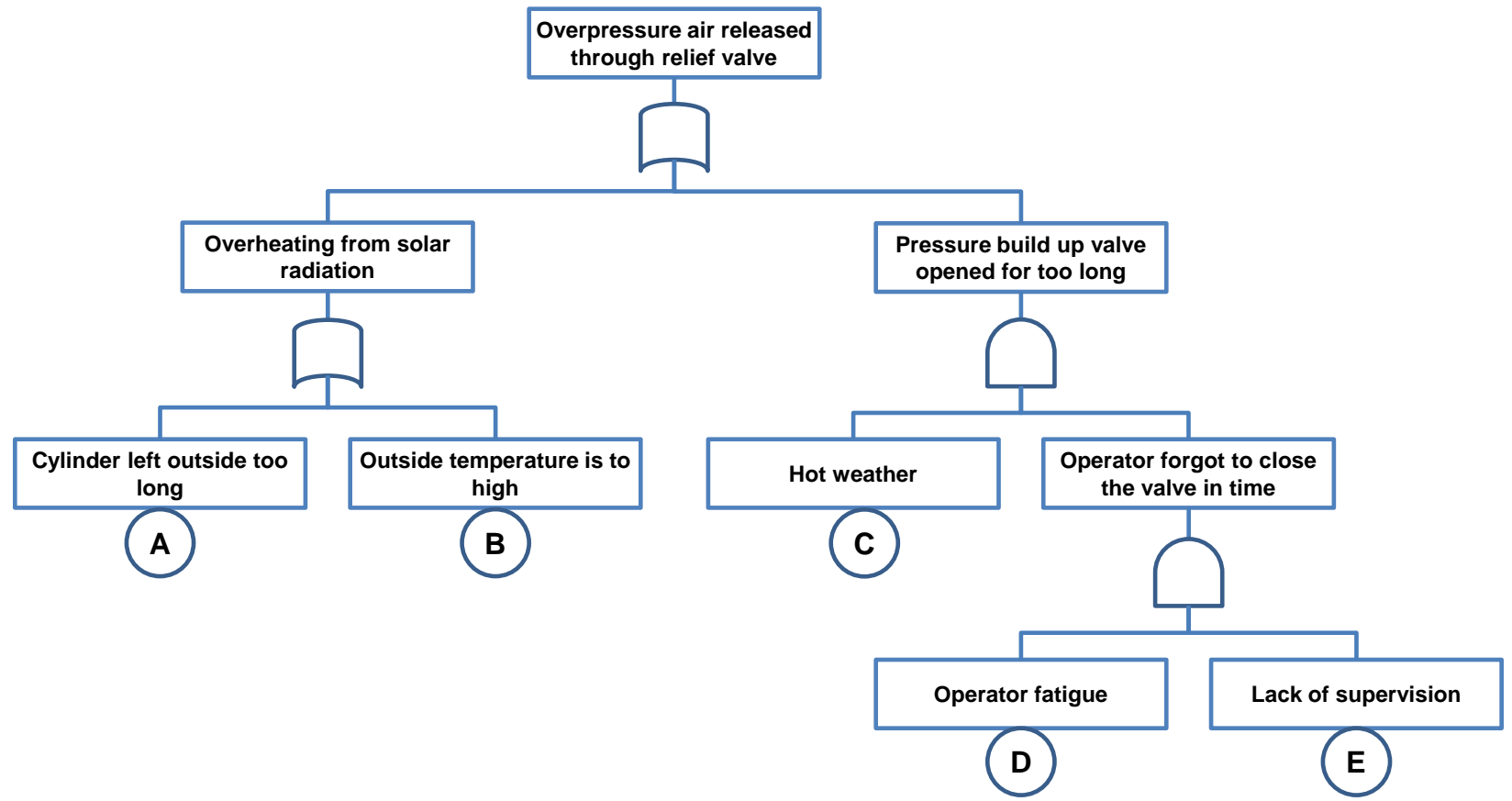

Figure 9: Fault Tree Analysis for Near Miss 2

In this case, the passive safety barrier, which was the pressure relief valve installed on the top of cylinder, was challenged and triggered to prevent further worsen of the overpressure scenario. The root cause analysis of the event has revealed that the valve had been left open for too long without control, which led to a challenge to the safety system. The basic event also indicated that for operation under such extreme environmental condition (high temperature, heat, strong solar, etc.), appropriate handover shift should be developed. The potential control measures that could avoid this event would be to: (a) continuously monitor the pressure development of the cylinder 
remotely at the control room or (b) put in place a buddy/back to back system to have two operators and shifts.

\section{Near Miss 3: Lack of checklist during routine operation}

One research team member forgot to bring the laptop, which is used as the data acquisition system terminal, before the departure to the test site. Without the laptop, the experiment could not be performed on time. The research team had to drive back to the university to bring the laptop, which in turn, lead to an unexpected delay in the work.

The near miss can be understood as shown in Figure 10:

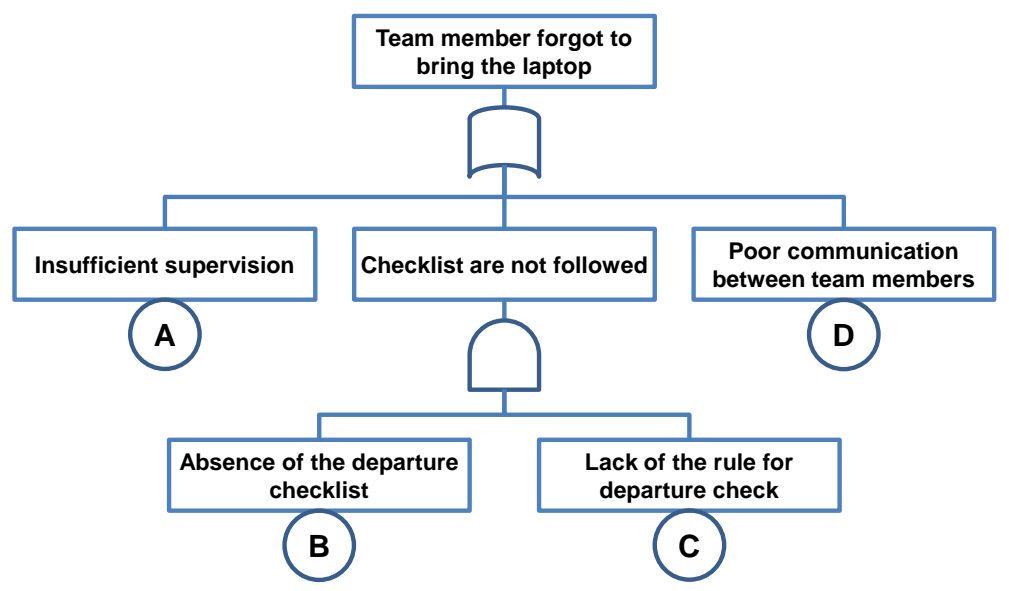

Figure 10: Fault Tree Analysis for Near Miss 3

In this case the checklist included laptop but was not followed. The root cause analysis process has revealed the weakness of research team's checking and verification process, and indicating poor safety culture. The basic event $\mathrm{A}$ and event $\mathrm{D}$ have indicated that communication and verification within the research team needs further enhancement, while event $B$ and event $C$ have shown the gap between the existing checklist setup and effective safe operation for routine operation in the field.

\section{Learning and conclusions}

This exercise has exposed students to many aspects of process safety principles. First, the substitution principle of Inherently Safer Design was practiced by selecting a less hazardous material, which were $\mathrm{LN}_{2}$ and $\mathrm{LO}_{2}$ as safer analogues of LNG. Second, some elements of safety management were learnt and practiced throughout the exercise. Process safety information to perform process hazard analysis were prepared and compiled. Hazard identification including the development of possible and credible leak/spill events, consequence analysis of potential hazardous events, estimation of the frequency of the incidents and risk analysis against acceptability criteria were learnt by doing and practiced during the project. Based on the risk analysis, safer experimental operational procedures were developed. The risks of performing the experiments were communicated in both written reports and in meetings with the appropriate authority. The experience of dealing with external contractors was gained and it was learnt that this is very important part of process safety and quality management. The development of 
emergency response planning was performed and the discussion with the real professional response team was a very good experience to learn from. Incidents investigation was performed after the experiments, lessons have been learnt and improvements were proposed.

Thus, if not all, many process safety key issues were identified during this experimental work, which help to improve a process safety culture in research laboratories and improve understanding of the key principles of process safety and their application throughout the life cycle of the experimental study.

Risk communication is another important aspect of good safety culture. After performing the experiments, the student involved in the work presented the results of the incident investigation to the research group mainly composed of other graduate and undergraduate students to share the experience gained.

Safety culture at the University could be improved significantly if future experimental work was performed with application of safety management principles similarly to in the study presented in this paper. In fact, performing an experiment at the University is very similar to building a project in the industry, but at a much smaller scale. The safety culture of an organization or group can be evaluated based on their knowledge of the process safety and how aggressively they apply this knowledge on day to day basis. Finally, it is to be noted that none of the incidents discussed above had the potential to cause devastating damage to the life or property. However the analysis of the failures or near misses has been found extremely useful for future safe operations of the system.

\section{Acknowledgements}

The authors would like to acknowledge the financial, support provided by Qatar National Research Fund (QNRF) for the LNG safety research being conducted at Texas A\&M University at Qatar (TAMU at Qatar). They also acknowledge the support of Qatar Petroleum in the form of the facilities used for experiments at RLIC and the provision of staff to work with the research team, which support many times exceeded our expectations.

\section{References}

[1] US Chemical Safety Board, “CSB Report No. 2005-04-I-TX: Investigation report on BP Texas City Refinery Explosion and Fire,” 2007.

[2] US Chemical Safety Board, “CSB Report No 2010-08-I-WA: Investigation report on Tesoro Anacortes Refinery incident - catastrophic rupture of heat exchanger,” 2014.

[3] R. Brown and H. Holmes, "The use of a factor-analytic procedure for assessing the validity of an employee safety climate model,” Accid. Anal. Prev., vol. 18, p. Accident Analysis and Prevention, 1986.

[4] D. Zohar, "Safety climate in industrial organizations: theoretical and applied implications.,” J. Appl. Psychol., vol. 65(1), pp. 96 - 102, 1980.

[5] G. Grote and C. Künzler, "Diagnosis of safety culture in safety management audits,” Saf. Sci., vol. 34, no. 1-3, pp. 131-150, 2000. 
[6] US Chemical Safety Board, “CSB Report No. 2010-05-I-TX: Texas Tech University Laboratory Explosion,” No. 2010-05-I-TX, 2011.

[7] J. Johnson, "University lab accident under investigation," Chem. Eng. News, vol. 88, no. 4, 2010.

[8] European Union, Seveso III Directive: DIRECTIVE 2012/18/EU OF THE EUROPEAN PARLIAMENT AND OF THE COUNCIL of 4 July 2012 on the control of major-accident hazards involving dangerous substances, amending and subsequently repealing Council Directive 96/82/EC, 2015th ed. 2012, pp. 1-37.

[9] American National Standards Institute (ANSI), Occupational Health and Safety Management Systems. USA: American Society of Safety Engineers (ASSE), 2012.

[10] British Standards Institution, Occupational health and safety management systems Requirements, 2007th ed. BSI Standards Publication, 2007.

[11] Occupational Safety and Health Administration, Process Safety Management of Highly Hazardous Chemicals Standard. USA, US, 2012.

[12] ANSI/API RP 754, Process Safety Performance Indicators for the Refining and Petrochemical Industries. 2010. 